\title{
MANAGING A 5G MOBILE PHONE SUPPLY CHAIN UNDER THE IMPACT OF STRATEGIC CONSUMERS: A TWO-PERIOD GAME ANALYSIS AND APPLICATIONS
}

\author{
ZiJian He, Junhai Ma AND Qin ZhanG*
}

\begin{abstract}
Consumers' strategic purchasing behavior has a great influence on the pricing and sales of new products. In order to study the impact of strategic consumers on the sales of $5 \mathrm{G}$ mobile phones, we establish a two-period pricing model. The supply chain contains two manufacturers, a communications operator and a mobile phone retailer. Cases where two manufacturers have the same or different pricing rights are researched by using the Stackelberg game and the Nash game model. Our research results are as follows: (1) We obtain the optimal 5G communication fees in two periods and find out how they change with the proportion of consumers changing. (2) We figure out the profits of the supply chain in two periods and analyze them. We find that the communication operator earns more than the others most of the time. (3) We investigate how the proportion of strategic consumer impact on supply chain profits and conclude that the optimal price and demand in a period will decrease as the proportion of consumers who only purchase products in the other period increases.
\end{abstract}

Mathematics Subject Classification. 91A10, 93A30.

Received August 2, 2020. Accepted March 21, 2021.

\section{INTRODUCTION}

It is known that every advancement in communication technology causes a huge change in human life. The promotion and application of $4 \mathrm{G}$ have changed people's lifestyle in the past five years. The rise of the Internet of Things has changed both our life and business models [12]. And when 4G has been fully popularized, 5G arrived. In 2019, the year of the beginning of 5G, major communication operators have launched their own 5G services and stepped up the construction of base stations. At the same time, various mobile phone manufacturers, such as Huawei, have successively launched their own 5G mobile phones. Manufacturers like Xiaomi and OPPO are also eager to get a share of this new market. In 2018, 7.9 billion mobile phones were sold to consumers worldwide, among which 1.6 billion were purchased by Chinese consumers. In 2019, cumulative sales worldwide were 8.3 billion mobile phones [10]. China is the world's largest mobile phone producer and owns the most consumers [9]. It is necessary to research such a huge market.

Consumers' purchasing behavior is always affected by not only the existing products' expected price but the performance of next-generation products as well. When a new product is launched, consumers must have

Keywords. Strategic consumers, two-period pricing, Stackelberg game, Nash game.

College of Management and Economics, Tianjin University, Tianjin 300072, P.R. China.

*Corresponding author: qzhang170531@126.com 
enough reasons to buy it to replace the product in their hands, otherwise, they will choose to delay the purchase decision and buy the next generation of products in the future. Maeng et al. [18] pointed out that the main reasons affecting consumers to purchase $5 \mathrm{G}$ services are excessive costs and insufficient demand. Considering the consumer's strategy, it is significant for the mobile phone manufacturers and the communication operator to price their products or service accurately.

The observations motivated us to explore how strategic consumers impact the $5 \mathrm{G}$ mobile phone supply chain. In our research, we establish a three-tier 5G mobile phone supply chain model. The supply chain contains two manufacturers, a communications operator and a mobile phone retailer. We divide the sale cycle into two periods, namely the early stage of $5 \mathrm{G}$ technology (period 1) and the mature stage of $5 \mathrm{G}$ technology (period 2). In each period, the communication operator will formulate different communication fee standards firstly. Then the two manufacturers will launch their own products, set prices and sell them through the mobile phone retailer.

According to consumers' purchasing behavior in each period, they are divided into three types. The first type of consumers includes those who only buy a $5 \mathrm{G}$ mobile phone in the first period, the second type of consumers includes those who only purchase a product in the second period, and the third type of consumers includes those who purchase phones in both periods.

A wholesale price contract is signed between the manufacturers and the retailer, and a commission is earned by the retailer on each mobile phone sold at the profit rate specified in the contract. Due to the different or the same pricing power of the two manufacturers, a Stackelberg game model (defined as "Model S") and a Nash game (defined as "Model N") between the two manufacturers are constructed.

Based on our models, the following issues are studied:

(1) Considering the existence of strategic consumers in the market, how do the manufacturers and the communication operator price their phones and service in the two periods?

(2) How does the proportion of strategic consumers impact on the profits of the supply chain?

In our research, we innovatively add a communication operator to the supply chain and research the impact of communication costs on the mobile phone supply chain. We obtain the profits of the supply chain in two periods. In addition, we also obtain the optimal prices of the mobile phones and the optimal communication fees in two periods. Besides, we investigate how these results change with the proportion of strategic consumers. The results of these studies will help $5 \mathrm{G}$ mobile phone manufacturers and communication operators to formulate optimal strategies, while also giving consumers guidance.

The remainder of this paper is organized as following. Section 2 reviews previous research; Section 3 introduces the model, Section 4 derives the optimal decisions of the supply chain, and Section 5 compares the equilibrium results by numerical examples. Section 6 presents the management insight of our research. Section 7 summarizes the conclusions and looks forward to the application prospects of the research.

\section{Literature REVIEW}

There are two main directions for the literature review mainly designed by our research: (1) Strategic consumers. (2) Two-period pricing. We conduct research on the relevant literature and point out how our research fills in the gaps of previous research.

\subsection{Strategic consumers}

Strategic consumers are those who not only consider the current value of the product, but also the value of the product after the purchase and the value of the new product. Therefore, they will adopt a strategy of delaying purchase. Nowadays, researches on strategic consumers have been carried out in economics, marketing, and other disciplines.

Zaman and Zaccour [25] studied how the government formulate a car scrap subsidy program the consumers are strategic. They researched the two-stage game between consumers and the government and determined the 
best subsidy level. The results show that the subsidy level in the second period is higher than that in the first period

Farshbaf-Geranmayeh and Zaccour [7] established a multi-period model that studies pricing and advertising decisions in the supply chain in the presence of short-sighted and strategic consumers. They assumed that the retailer's advertising will have a positive effect on consumers' willingness to pay at a decreasing rate over time. It turns out that the manufacturer influences the retailer's pricing policy by changing his participation rate.

Lei et al. [13] studied the impact of the existence of strategic consumers on the dual-channel supply chain and analyzed the retailer's optimal strategy and maximum return under the delayed purchasing behavior of consumers. Xie et al. [24] studied the cooperation of the supply chain under the condition of uncertain market demand due to the existence of strategic consumers. Bao et al. [2] studied the impact of the low-carbon preference of strategic consumers on the government subsidy in the vehicle market.

Liu et al. [15] studied the effect of companies using trade-in items and dynamic or static pricing in product markets with intertemporal demand. The study found that static pricing is more suitable for strategic consumers, and dynamic pricing will increase the long-term profit of enterprises. Papanastasiou and Savva [22] studied how social learning influences purchasing strategies within a two-period supply chain model. They found that if consumers are short-sighted, companies are more inclined to reduce prices. If there are enough strategic consumers, the company's static pricing is higher than the dynamic pricing. In addition, if consumers conduct extensively social learning, companies should use dynamic pricing methods. Cachon and Feldman [3] studied three pricing strategies: static pricing, discount pricing and dynamic pricing, and analyzed the impact of corporate pricing strategies on corporate earnings in the presence of strategic consumers.

Parlaktürk [21] studies the impact of strategic consumer behavior when companies sell products differentiated in two periods. They found that the behavior of strategic consumers will reduce the profit of the company, and the reduced profit is positively related to the number of products sold by the company.

In most research works of strategic consumers, a two-period pricing model is used. Our research is the same. The reason is that the single-period sales model cannot express consumers' purchasing decisions. Our classification of consumers is different from previous researches. In some studies, consumers are divided according to whether consumers have foresight, or according to consumers' purchasing power. We divide consumers according to the period of their purchase. The advantage is that this division makes it easier for manufacturers to investigate the market. They can easily know the proportion of consumers who bought products in various periods through market surveys or historical data surveys.

\subsection{Two-period pricing}

Li et al. [14] studied the discount strategies of online retailers in response to strategic consumers. They establish a two-period model to study three online coupon strategies. They found that the existence of strategic consumers will increase the product prices for two-period.

Zhou [27] studied the two-period pricing of fashion products. A fashion company will launch products to the market in the first period and adopt three different pricing measures in the second period: (1) Do not launch new models. (2) Launch new styles and stop selling old styles. (3) Introduce new styles and sell both styles simultaneously. The study found which measures to take is related to consumers' psychological expectations and production costs. Genc and De Giovanni [8] established a two-period closed-loop supply chain to study the impact of return policies on two-period sales. In this model, product return rates are related to product quality and price. Studies have found that adopting a more proactive return policy is always good for the business. Cheng et al. [4] studied a two-period sales model for deteriorating items. They divided the product sales cycle into two periods, the two-phase advance sales period and the spot sales period. The optimal pricing and inventory decisions in two periods were studied and the results were simulated in their research.

Ma et al. [16] established a supply chain for new energy vehicles and research the impacts of pricing time on profitability and stability. Maiti and Giri [19] studied a market where the demand rate depends on prices and established a secondary supply chain between manufacturers and retailers. Manufacturers use one of two pricing methods: (1) Set the same wholesale price for both sales periods. (2) Set different wholesale prices 


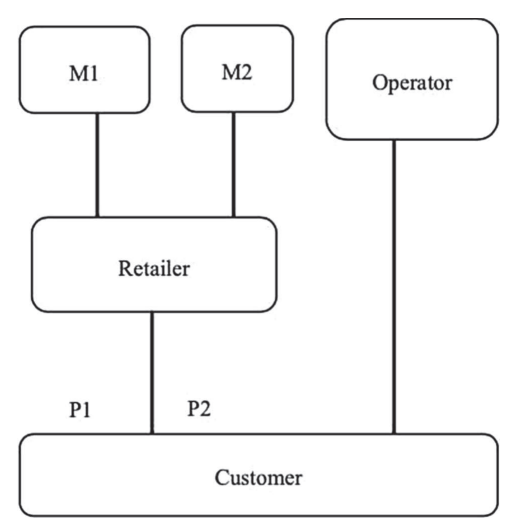

FIGURE 1. Supply chain structure diagram.

during the two sales periods. They studied the impact of these decision strategies on the best outcomes of the supply chain. Dong and Wu [6] examined how the behavior of strategic consumers in the two-period pricing and inventory decisions in the rapid response system affects the supply chain. The influence of strategic consumers on pricing strategies and inventory strategies is studied. The research finds that strategic consumers are beneficial to enterprises under certain conditions. Zha et al. [26] investigated the intertemporal and horizontal reference price effect (RPE), formed by the historical price and the competitor's price, will affect the optimal pricing strategy. They established a duopoly game to find out that how the iRPE and hRPE impact on the optimal price in two-period pricing. Ma et al. [17] established a game model of duopoly car manufacturers, using carbon emission reduction policy constraints as the research background, and explored how electric vehicles and fuel vehicles compete on product performance in the delayed pricing decisions of strategic consumers.

Previous research works on the two-stage pricing of the mobile phone supply chain have never involved the study of the pricing of communication operators. Our article fills this gap. Our research uses the traditional linear demand function to solve the optimal prices. The Nash game model and the Stackelberg game model are used to model the pricing games between the manufacturers with the same or different pricing power.

\section{MOdeL}

In our research, a supply chain that includes two manufacturers, a communication operator and a mobile phone retailer is constructed.

The communication operator provides consumers with services of communication service and charges for traffic. A wholesale price contract is signed between the retailer and the manufacturers. The retailer earns a portion negotiated between the manufacturers and the retailer of the price of each phone. In each period, the communication operator firstly announces the price of the communication service it provides. And then, the price leading manufacturer will first launch and price its products and the price follower will second set their own product's price if the manufacturers' pricing power is different. Otherwise, the two manufacturers will make their decisions simultaneously. The supply chain structure is shown in Figure 1.

At each level, competition in the mobile phone market is often only carried out among a few mobile phone manufacturers. For example, in the high-end mobile phone market, it is mainly the market competition between Huawei mobile phones and Apple mobile phones. In the mid- and low-end mobile phone market, it is mainly the competition between Xiaomi mobile phones and Honor mobile phones. The research in this article only considers the only non-specific level. Considering the above factors, when establishing the $5 \mathrm{G}$ mobile phone supply chain model, the number of mobile phone manufacturers is set to two.

Unlike other electronic products, the use of mobile phones must rely on communication operators to provide communication signal services. Therefore, research on the sales of $5 \mathrm{G}$ mobile phones must pay attention to the 
TABLE 1. Notations.

\begin{tabular}{ll}
\hline \hline Notations & Symbols \\
\hline Total number of consumers in the market & $A$ \\
Demand for the first period & $D_{1}^{\mathrm{I}}, D_{2}^{\mathrm{I}}$ \\
Demand for the second period & $D_{1}^{\mathrm{II}}, D_{2}^{\mathrm{II}}$ \\
Two-period manufacturing cost & $c_{1}, c_{2}$ \\
Percentage of consumers who bought only in the first period & $\alpha_{1}$ \\
Percentage of consumers who bought only in the second period & $\alpha_{2}$ \\
Percentage of consumers who bought both periods & $1-\alpha_{1}-\alpha_{2}$ \\
Product competition coefficient & $\gamma$ \\
Communication fee coefficient & $\lambda$ \\
Communication tariff & $\beta_{1}, \beta_{2}$ \\
Retailer profit margins & $r_{1}, r_{2}$ \\
Manufacturer profit & $\pi_{m 1}^{\mathrm{I}}, \pi_{m 1}^{\mathrm{II}}, \pi_{m 2}^{\mathrm{I}}, \pi_{m 2}^{\mathrm{II}}$ \\
Operator profit & $\pi_{O}^{\mathrm{I}}, \pi_{O}^{\mathrm{II}}$ \\
Retailer profit & $\pi_{R}^{\mathrm{I}}, \pi_{R}^{\mathrm{II}}$ \\
\hline
\end{tabular}

existence of communication operators. Because the cost of $5 \mathrm{G}$ communication is an issue that most consumers have to consider when buying $5 \mathrm{G}$ mobile phones. Therefore, this article adds a communication operator to the supply chain of $5 \mathrm{G}$ mobile phones, and the communication operator provides consumers with communication signal services and charges a certain fee. The meanings of the mathematical symbols in this paper are shown in Table 1.

We describe the total number of consumers in the market with $4 \mathrm{G}$ or previous mobile phones as $A$. All of them will purchase $5 \mathrm{G}$ phones in the first period or second period or both of them. When the $5 \mathrm{G}$ mobile phone is launched, consumers in the market will take different purchasing decisions. Some consumers will buy a $5 \mathrm{G}$ mobile phone as soon as it comes into the market and they will not buy a new phone in the second period, the proportion of these people is $\alpha_{1}$. Some, the proportion of them is $\alpha_{2}$, will choose to buy it in the second period. The proportion of the rest is $1-\alpha_{1}-\alpha_{2}$, and they will purchase mobile phones in both periods.

We use a linear demand function to represent the demand of products in two periods. The mobile phones' demand functions of the two manufacturers in the first period can be expressed as follows:

$$
\begin{aligned}
& D_{1}^{\mathrm{I}}=A\left(1-\alpha_{2}\right)-p_{\mathrm{I} 1}+\gamma p_{\mathrm{I} 2}-\lambda \sqrt{\beta_{1}} \\
& D_{2}^{\mathrm{I}}=A\left(1-\alpha_{2}\right)-p_{\mathrm{I} 2}+\gamma p_{\mathrm{I} 1}-\lambda \sqrt{\beta_{1}} .
\end{aligned}
$$

The parameter $\lambda$ represents the degree of market competition between the products of the two manufacturers. The mobile phones' demand functions of the two manufacturers in the second period can be represented as follows:

$$
\begin{aligned}
& D_{1}^{\mathrm{II}}=A\left(1-\alpha_{1}\right)-p_{\mathrm{II} 1}+\gamma p_{\mathrm{II} 2}-\lambda \beta_{2}^{2} \\
& D_{2}^{\mathrm{II}}=A\left(1-\alpha_{1}\right)-p_{\mathrm{II} 2}+\gamma p_{\mathrm{II} 1}-\lambda \beta_{2}^{2}
\end{aligned}
$$

where $p_{i j}$ is the production's price of the manufacturer $j$ in Period $i$, where $i=\mathrm{I}$, II and $j=1,2$. Here I and II denote the first period and the second period, respectively.

We have considered the impact of the operator's communication fee on the demand for $5 \mathrm{G}$ mobile phones. Due to the lack of base stations and high costs in the beginning of a new technique, the communication fee in the first period is higher than that in the second period. According to Kalyanaram [11], considering that consumers are more sensitive to the price during the maturity period of new technologies than in the early 
periods of application, the impact of communication fee on demand is diminishing marginally in the first period and increasing marginally in the second period. We add price sensitivity coefficient $\lambda \sqrt{\beta_{1}}$ to the first period's demand model as well as $\lambda \beta_{2}^{2}$ to the second period's. In addition, for the convenience of subsequent research, $A$ can be set to $A=1$.

In this paper, the costs of $5 \mathrm{G}$ mobile phones produced by two manufacturers are the same in the same period. And the profits of manufacturer $i$ in both periods $(i=1,2)$ are as follows:

$$
\begin{aligned}
& \pi_{M 1}^{\mathrm{I}}=\left(\left(1-r_{1}\right) p_{\mathrm{I} 1}-c_{1}\right)\left(\left(1-\alpha_{2}\right)-p_{\mathrm{I} 1}+\gamma p_{\mathrm{I} 2}-\lambda \sqrt{\beta_{1}}\right) \\
& \pi_{M 2}^{\mathrm{I}}=\left(\left(1-r_{1}\right) p_{\mathrm{I} 2}-c_{1}\right)\left(\left(1-\alpha_{2}\right)-p_{\mathrm{I} 2}+\gamma p_{\mathrm{I} 1}-\lambda \sqrt{\beta_{1}}\right) \\
& \pi_{M 1}^{\mathrm{II}}=\left(\left(1-r_{2}\right) p_{\mathrm{II} 1}-c_{2}\right)\left(\left(1-\alpha_{1}\right)-p_{\mathrm{II} 1}+\gamma p_{\mathrm{II} 2}-\lambda \beta_{2}^{2}\right) \\
& \pi_{M 2}^{\mathrm{II}}=\left(\left(1-r_{2}\right) p_{\mathrm{II} 2}-c_{2}\right)\left(\left(1-\alpha_{1}\right)-p_{\mathrm{II} 2}+\gamma p_{\mathrm{II} 1}-\lambda \beta_{2}^{2}\right) .
\end{aligned}
$$

In reality, communication fees are usually charged on a monthly basis. But in our study, we set it as a onetime fee for the convenience of research. The operator is a communication service provider, where its profits and costs are very complicated. For the purpose of this study, we assume that its profit source is the sum of the communication costs of each mobile phone. The communication operator's two-period profits are as following:

$$
\begin{aligned}
& \pi_{O}^{\mathrm{I}}=\left(D_{1}^{\mathrm{I}}+D_{2}^{\mathrm{I}}\right) \beta_{1} \\
& \pi_{O}^{\mathrm{II}}=\left(D_{1}^{\mathrm{II}}+D_{2}^{\mathrm{II}}\right) \beta_{2} .
\end{aligned}
$$

Niederhoff et al. [20] find that manufacturers indicate a high degree of concern for fairness instead of profits when they sign a wholesale contract with retailers. In our paper, the retailer has the power to set the ratio of wholesale contracts. At each period, the retailer signs a wholesale price contract with both manufacturer 1 and manufacturer 2. For both manufacturers, the coefficients are the same. The wholesale price coefficient of the contract is $r_{i}$. The retailer's two-period profits are as follows:

$$
\begin{aligned}
& \pi_{R}^{\mathrm{I}}=r_{1}\left(p_{1}^{\mathrm{I}} D_{1}^{\mathrm{I}}+p_{2}^{\mathrm{I}} D_{2}^{\mathrm{I}}\right) \\
& \pi_{R}^{\mathrm{II}}=r_{2}\left(p_{1}^{\mathrm{II}} D_{1}^{\mathrm{II}}+p_{2}^{\mathrm{II}} D_{2}^{\mathrm{II}}\right) .
\end{aligned}
$$

\section{Decisions of the SUPPly Chain}

\subsection{Stackelberg game of two manufacturers (Model S)}

When the two manufacturers own different pricing power, they play a Stackelberg game. Before the manufacturers make their decisions, the communication will announce the communication fee. Then, manufacturer 1 launches its $5 \mathrm{G}$ mobile phone and sets the price. After that, manufacturer 2 would set its product's price based on the Manufacturer 1's decision (see Fig. 2). To solve this game requires the use of reverse recursion.

Proposition 4.1. In the Model $S$, the prices, demands and profits of the two manufacturers are given respectively by:

$$
\begin{aligned}
p_{1}^{\mathrm{SI}} & =\frac{\left(10+\gamma-5 \gamma^{2}\right) c_{1}+(2+\gamma)\left(-1+r_{1}\right)\left(-1+\alpha_{2}\right)}{6\left(-2+\gamma^{2}\right)\left(-1+r_{1}\right)} \\
p_{2}^{\mathrm{SI}} & =\frac{\left(-20-2 \gamma+9 \gamma^{2}+\gamma^{3}\right) c_{1}+\left(-4-2 \gamma+\gamma^{2}\right)\left(-1+r_{1}\right)\left(-1+\alpha_{2}\right)}{12\left(-2+\gamma^{2}\right)\left(1-r_{1}\right)} \\
D_{1}^{\mathrm{SI}} & =\frac{(2+\gamma)\left((-1+\gamma) c_{1}+\left(-1+r_{1}\right)\left(-1+\alpha_{2}\right)\right)}{12\left(1-r_{1}\right)} \\
D_{2}^{\mathrm{SI}} & =\frac{\left(-4-2 \gamma+\gamma^{2}\right)\left((-1+\gamma) c_{1}+\left(-1+r_{1}\right)\left(-1+\alpha_{2}\right)\right)}{12\left(-2+\gamma^{2}\right)\left(1-r_{1}\right)}
\end{aligned}
$$




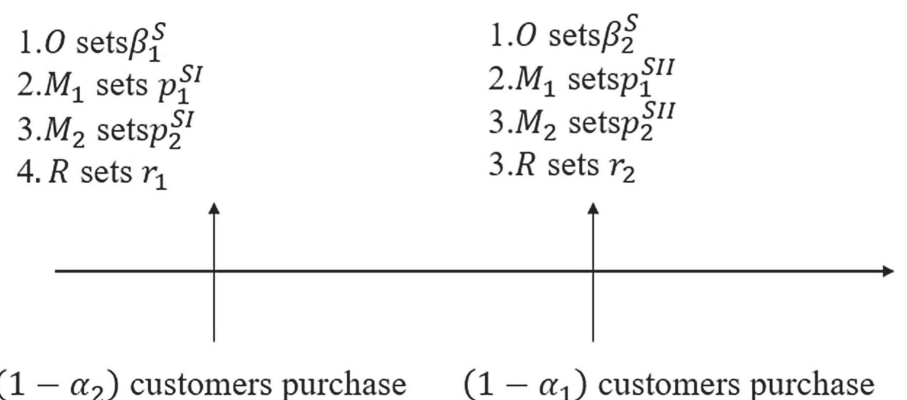

Figure 2. Decision making sequence in the Model S.

1.0 sets $\beta_{1}^{N}$

2. $M_{1}$ sets $p_{1}^{N I}$ and $M_{2}$ sets $p_{2}^{N I}$

3. $R$ sets $r_{1}$
$1.0 \operatorname{sets} \beta_{2}^{N}$

$2 . M_{1} \operatorname{sets} p_{1}^{N I I}$ and $M_{2}$ sets $p_{2}^{N I I}$

3. $R$ sets $r_{2}$

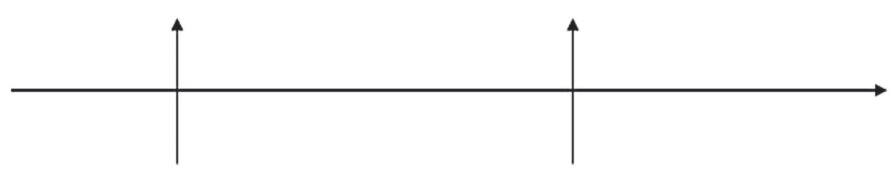

$\left(1-\alpha_{2}\right)$ customers purchase $\quad\left(1-\alpha_{1}\right)$ customers purchase

FiguRE 3. Decision making sequence in the Model N.

$$
\begin{aligned}
\pi_{M_{1}}^{\mathrm{SI}} & =\frac{(2+\gamma)^{2}\left((-1+\gamma) c_{1}+\left(-1+r_{1}\right)\left(-1+\alpha_{2}\right)\right)^{2}}{72\left(-2+\gamma^{2}\right)\left(-1+r_{1}\right)} \\
\pi_{M_{2}}^{\mathrm{SI}} & =\frac{\left(-4-2 \gamma+\gamma^{2}\right)^{2}\left((-1+\gamma) c_{1}+\left(-1+r_{1}\right)\left(-1+\alpha_{2}\right)\right)^{2}}{144\left(-2+\gamma^{2}\right)^{2}\left(1-r_{1}\right)} .
\end{aligned}
$$

Taking the partial derivative of the price and demand of the products in the first period to the proportion of consumers, we can get that $\frac{\partial p_{1}^{\mathrm{SI}}}{\partial \alpha_{2}}=\frac{2+\gamma}{6\left(-2+\gamma^{2}\right)}<0, \frac{\partial \partial_{2}^{\mathrm{SI}}}{\partial \alpha_{2}}=\frac{\left(-4-2 \gamma+\gamma^{2}\right)}{12\left(2-\gamma^{2}\right)}<0, \frac{\partial D_{1}^{\mathrm{SI}}}{\partial \alpha_{2}}=\frac{1}{12}(-2-\gamma)<0$ and $\frac{\partial D_{2}^{\mathrm{SI}}}{\partial \alpha_{2}}=\frac{-4-2 \gamma+\gamma^{2}}{12\left(2-\gamma^{2}\right)}<0$. This shows that in the first period, as the proportion of consumers who only buy mobile phones in the second stage increases, the price and demand for mobile phones from both manufacturers will decrease.

The prices, demands and profits of the two manufacturers of the second period are given respectively by:

$$
\begin{aligned}
p_{1}^{\mathrm{SII}} & =\frac{\left(4+\gamma-2 \gamma^{2}\right) c_{2}+(2+\gamma)\left(-1+r_{2}\right)\left(-1+\alpha_{1}\right)}{3\left(-2+\gamma^{2}\right)\left(-1+r_{2}\right)} \\
p_{2}^{\mathrm{SII}} & =\frac{\left(-8-2 \gamma+3 \gamma^{2}+\gamma^{3}\right) c_{2}+\left(-4-2 \gamma+\gamma^{2}\right)\left(-1+r_{2}\right)\left(-1+\alpha_{1}\right)}{6\left(-2+\gamma^{2}\right)\left(1-r_{2}\right)} \\
D_{1}^{\mathrm{SII}} & =\frac{(2+\gamma)\left((-1+\gamma) c_{2}+\left(-1+r_{2}\right)\left(-1+\alpha_{1}\right)\right)}{6\left(1-r_{2}\right)} \\
D_{2}^{\mathrm{SII}} & =\frac{\left(-4-2 \gamma+\gamma^{2}\right)\left((-1+\gamma) c_{2}+\left(-1+r_{2}\right)\left(-1+\alpha_{1}\right)\right)}{6\left(-2+\gamma^{2}\right)\left(1-r_{2}\right)}
\end{aligned}
$$




$$
\begin{aligned}
\pi_{M_{1}}^{\mathrm{SII}} & =\frac{(2+\gamma)^{2}\left((-1+\gamma) c_{2}+\left(-1+r_{2}\right)\left(-1+\alpha_{1}\right)\right)^{2}}{18\left(-2+\gamma^{2}\right)\left(-1+r_{2}\right)} \\
\pi_{M_{2}}^{\mathrm{SII}} & =\frac{\left(-4-2 \gamma+\gamma^{2}\right)^{2}\left((-1+\gamma) c_{2}+\left(-1+r_{2}\right)\left(-1+\alpha_{1}\right)\right)^{2}}{36\left(-2+\gamma^{2}\right)^{2}\left(1-r_{2}\right)}
\end{aligned}
$$

Taking the partial derivative of the price and demand of the products in the second period to the proportion of consumers, we can obtain that $\frac{\partial p_{1}^{\text {SII }}}{\partial \alpha_{1}}=\frac{2+\gamma}{3\left(-2+\gamma^{2}\right)}<0, \frac{\partial p_{2}^{\text {SII }}}{\partial \alpha_{1}}=\frac{-4-2 \gamma+\gamma^{2}}{6\left(2-\gamma^{2}\right)}<0, \frac{\partial D_{1}^{\mathrm{SII}}}{\partial \alpha_{2}}=\frac{1}{6}(-2-\gamma)<0$ and $\frac{\partial D_{2}^{\mathrm{SII}}}{\partial \alpha_{2}}=\frac{-4-2 \gamma+\gamma^{2}}{6\left(2-\gamma^{2}\right)}<0$. This means that in the second period, as the proportion of consumers who only buy mobile phones in the first period increases, the price and demand for mobile phones from both manufacturers will decrease.

The retailer's two-period profits are as follow:

$$
\begin{aligned}
\pi_{R}^{\mathrm{SI}}= & \frac{1}{-144\left(-2+\gamma^{2}\right)^{2}\left(-1+r_{1}\right)^{2}} r_{1}\left((-1+\gamma) c_{1}+\left(-1+r_{1}\right)\left(-1+\alpha_{2}\right)\right)\left(-\left(160+96 \gamma-128 \gamma^{2}-68 \gamma^{3}\right.\right. \\
& \left.\left.+25 \gamma^{4}+11 \gamma^{5}\right) c_{1}+\left(-32-32 \gamma+8 \gamma^{2}+12 \gamma^{3}+\gamma^{4}\right)\left(-1+r_{1}\right)\left(-1+\alpha_{2}\right)\right) \\
\pi_{R}^{\mathrm{SII}}= & \frac{1}{-36\left(-2+\gamma^{2}\right)^{2}\left(-1+r_{2}\right)^{2}} r_{2}\left((-1+\gamma) c_{2}+\left(-1+r_{2}\right)\left(-1+\alpha_{1}\right)\right)\left(-\left(64+48 \gamma-44 \gamma^{2}-32 \gamma^{3}\right.\right. \\
& \left.\left.+7 \gamma^{4}+5 \gamma^{5}\right) c_{2}+\left(-32-32 \gamma+8 \gamma^{2}+12 \gamma^{3}+\gamma^{4}\right)\left(-1+r_{2}\right)\left(-1+\alpha_{1}\right)\right) .
\end{aligned}
$$

The two-period profits of the communication operator are as follow:

$$
\begin{aligned}
\pi_{O}^{\mathrm{SI}} & =\frac{\left(-8-4 \gamma+3 \gamma^{2}+\gamma^{3}\right)\left((-1+\gamma) c_{1}+\left(-1+r_{1}\right)\left(-1+\alpha_{2}\right)\right)^{3}}{27\left(-2+\gamma^{2}\right) \lambda^{2}\left(1-r_{1}\right)^{3}} \\
\pi_{O}^{\mathrm{SII}} & =\frac{\left(-8-4 \gamma+3 \gamma^{2}+\gamma^{3}\right)\left((-1+\gamma) c_{2}+\left(-1+r_{2}\right)\left(-1+\alpha_{1}\right)\right) \sqrt{\frac{\left(1-\alpha_{1}\right)\left(1-r_{2}\right)+(-1+\gamma) c_{2}}{\lambda\left(1-r_{2}\right)}}}{6 \sqrt{3}\left(-2+\gamma^{2}\right)\left(1-r_{2}\right)} .
\end{aligned}
$$

Proof. The proof process can be found in Appendix A.

Proposition 4.2. In the Model $S$, when the cost of the products in the two periods is within a certain range, the communication fee of the communication operator is priced as follows.

(1) If $0<\alpha_{2}<\frac{-1+c_{1}-\gamma c_{1}+r_{1}}{-1+r_{1}}$ and $0<c_{1}<\frac{-1+r_{1}}{-1+\gamma}$, the Communication fee in the first period has an optimal value, $\beta_{1}=\frac{4\left((-1+\gamma) c_{1}+\left(-1+r_{1}\right)\left(-1+\alpha_{2}\right)\right)^{2}}{9 \lambda^{2}\left(-1+r_{1}\right)^{2}}$.

(2) If $0<\alpha_{1}<\frac{-1+c_{2}-\gamma c_{2}+r_{2}}{-1+r_{2}}$ and $0<c_{2}<\frac{-1+r_{2}}{-1+\gamma}$, the Communication fee in the second period has an optimal value, $\beta_{2}=\sqrt{\frac{(-1+\gamma) c_{2}+\left(-1+r_{2}\right)\left(-1+\alpha_{1}\right)}{3\left(1-r_{2}\right) \lambda}}$.

Proof. See Appendix 4.1.

Proposition 4.2 shows that in the Model S, only when the parameters $\alpha_{1}, \alpha_{2}, c_{1}$ and $c_{2}$ are within a certain range, there is an optimal value for the communication fee.

\subsection{Nash game of two manufacturers (Model N)}

Besides the competitions between the big and the small, there are many firms owning the same pricing power. They play a Nash game when they launch and price their new products. Figure 3 describes the sequence of the game. 
Proposition 4.3. In the Model $N$, the prices, demands and profits of the two manufacturers in the first period are given respectively by:

$$
\begin{aligned}
p_{1}^{\mathrm{NI}} & =p_{2}^{\mathrm{NI}}=\frac{(5-2 \gamma) c_{1}+\left(-1+r_{1}\right)\left(-1+\alpha_{2}\right)}{3(-2+\gamma)\left(-1+r_{1}\right)} \\
D_{1}^{\mathrm{NI}} & =D_{2}^{\mathrm{NI}}=\frac{(-1+\gamma) c_{1}+\left(-1+r_{1}\right)\left(-1+\alpha_{2}\right)}{3(-2+\gamma)\left(-1+r_{1}\right)} \\
\pi_{M_{1}}^{\mathrm{NI}} & =\pi_{M_{2}}^{\mathrm{NI}}=\frac{\left((-1+\gamma) c_{1}+\left(-1+r_{1}\right)\left(-1+\alpha_{2}\right)\right)^{2}}{9(-2+\gamma)^{2}\left(1-r_{1}\right)} .
\end{aligned}
$$

In the second period, the prices, demands and profits of the two manufacturers are given respectively by:

$$
\begin{aligned}
& p_{1}^{\mathrm{NII}}=p_{2}^{\mathrm{NII}}=\frac{(5-2 \gamma) c_{2}+2\left(-1+r_{2}\right)\left(-1+\alpha_{1}\right)}{3(-2+\gamma)\left(-1+r_{2}\right)} \\
& D_{1}^{\mathrm{NII}}=D_{2}^{\mathrm{NII}}=\frac{(-1+\gamma) c_{2}+2\left(-1+r_{2}\right)\left(-1+\alpha_{1}\right)}{3(-2+\gamma)\left(-1+r_{2}\right)} \\
& \pi_{M}^{\mathrm{NII}}=\pi_{M_{2}}^{\mathrm{NII}}=-\frac{\left((-1+\gamma) c_{2}+2\left(-1+r_{2}\right)\left(-1+\alpha_{1}\right)\right)^{2}}{9(-2+\gamma)^{2}\left(1-r_{2}\right)} .
\end{aligned}
$$

The two-period profits of the communication operator and the retailer are as follow:

$$
\begin{aligned}
\pi_{O}^{\mathrm{NI}} & =\frac{4\left((-1+\gamma) c_{1}+\left(-1+r_{1}\right)\left(-1+\alpha_{2}\right)\right)^{2}\left(2(-1+\gamma) c_{1}+\left(-1+r_{1}\right)\left(-1+\alpha_{2}\right)\right)}{27(-2+\gamma) \lambda^{2}\left(-1+r_{1}\right)^{3}} \\
\pi_{O}^{\mathrm{NII}} & =\frac{2\left((-1+\gamma) c_{2}+\left(-1+r_{2}\right)\left(-1+\alpha_{1}\right)\right) \sqrt{\frac{\left(1-\alpha_{1}\right)\left(1-r_{2}\right)+2(-1+\gamma) c_{2}}{\lambda\left(1-r_{2}\right)}}}{3 \sqrt{3}(-2+\gamma)\left(-1+r_{2}\right)} \\
\pi_{R}^{\mathrm{NI}} & =\frac{\left((-1+\gamma) c_{1}+\left(-1+r_{1}\right)\left(-1+\alpha_{2}\right)\right)\left(2(5-2 \gamma) c_{1} r_{1}+\left(-1+r_{1}\right)\left(-1+\alpha_{2}\right)\right)}{9(-2+\gamma)^{2}\left(-1+r_{1}\right)^{2}} \\
\pi_{R}^{\mathrm{NII}} & =\frac{\left((-1+\gamma) c_{2}+2\left(-1+r_{2}\right)\left(-1+\alpha_{1}\right)\right)\left(2(5-2 \gamma) c_{2} r_{2}+2\left(-1+r_{2}\right)\left(-1+\alpha_{1}\right)\right)}{9(-2+\gamma)^{2}\left(-1+r_{2}\right)^{2}} .
\end{aligned}
$$

Proof. The certification process of Proposition 4.3 is documented in Appendix B.

Proposition 4.4. In the Model $N$, when the production cost of the products in the two periods is within a certain range, the communication fee of the communication operator is priced as follows.

(1) If $0<\alpha_{2}<\frac{-1+c_{1}-\gamma c_{1}+r_{1}}{-1+r_{1}}$ and $0<c_{1}<\frac{-1+r_{1}}{-1+\gamma}$, the Communication fee in the first period has an optimal value, $\beta_{1}=\frac{4\left((-1+\gamma) c_{1}+\left(-1+r_{1}\right)\left(-1+\alpha_{2}\right)\right)^{2}}{9 \lambda^{2}\left(-1+r_{1}\right)^{2}}$.

(2) If $0<\alpha_{1}<\frac{-1+2 c_{2}-2 \gamma c_{2}+r_{2}}{-1+r_{2}}$ and $0<c_{2}<\frac{-1+r_{2}}{-2+2 \gamma}$, the Communication fee in the second period has an optimal value, $\beta_{2}=\sqrt{\frac{-1+2 c_{2}-2 \gamma c_{2}+r_{2}+\alpha_{1}-r_{2} \alpha_{1}}{3 \lambda\left(-1+r_{2}\right)}}$.

Proof. See Appendix B.

Proposition 4.5. (1) If $0<\alpha_{2}<\frac{-1+c_{1}-\gamma c_{1}+r_{1}}{-1+r_{1}}$ and $0<c_{1}<\frac{-1+r_{1}}{-1+\gamma}$, in the Models $S$ and $N$, the demand for the products of the two manufacturers in the first period is greater than 0 .

(2) If $\frac{-1+c_{2}-\gamma c_{2}+r_{2}}{-1+r_{2}}<\alpha_{1}<\frac{-2+c_{2}-\gamma c_{2}+2 r_{2}}{-2+2 r_{2}}$ and $\frac{-1+r_{2}}{-1+\gamma}<c_{2}<\frac{-2+2 r_{2}}{-1+\gamma}$. In the Model $N$, the demand for the products of the two manufacturers in the second period is greater than 0 . In Model $S$, the demand of the products of the two manufacturers in the second period is equal to 0. 
(3) If $0<\alpha_{1}<\frac{-1+c_{2}-\gamma c_{2}+r_{2}}{-1+r_{2}}$ and $0<c_{2}<\frac{-1+r_{2}}{-1+\gamma}$, in the Models $S$ and $N$, the demands for the products of the two manufacturers in the second period is greater than 0.

Proposition 4.5 indicates that in order to ensure that the market demand is big than 0 in both periods, manufacturers must control production costs within a certain range, while the proportion of consumers who only purchase a phone in the other period must be below a certain threshold. In the first period, the certain ranges of costs of the two models are the same, and the thresholds of proportion are the same, too. But in the second period, the ranges and thresholds of the two models are different.

\section{AnAlysis of the EQUILIBRIUM RESUlts}

\subsection{The impact of the percentage of consumers on the profits of the supply chain}

In order to better analyze the calculation results, we adopt a numerical simulation method to study the impact of parameters in the model on the results. First of all, we need to determine the value of each parameter. The parameter $\lambda$ represents the degree of market competition between the products of the two manufacturers, and its value is within the range of $\{\lambda \mid 0 \leq \lambda \leq 1\}$. In our experiments, we set its value to 0.3 to simulate a reasonable market competition. The parameter $\gamma$ indicates the degree of consumers' acceptance of the communication fee, and its value is within the range of $\{\gamma \mid 0 \leq \gamma \leq 1\}$. Its value does not affect the results of the experiment, we set its value to 0.8 . The parameters $r_{1}$ and $r_{2}$ represent the profit margin of the wholesale price contract between the manufacturer and the retailer in the two periods, and we set their values to 0.1. We have discussed the value range of the manufacturer's cost before, and the value of other parameters can be brought into the equation to obtain the value range of the manufacturer's production cost in two periods $\left(c_{1} \in\left\{c_{1} \mid 0 \leq c_{1} \leq \frac{-1+r_{1}}{-1+\gamma}\right\}, c_{2} \in\left\{c_{2} \mid 0 \leq c_{2} \leq \frac{-1+r_{2}}{-2+2 \gamma}\right\}\right)$. We take their values as 0.9 and 0.7 respectively. According to the values of these parameters, we can find the range of values of $\alpha_{1}$ and $\alpha_{2}\left(\alpha_{1} \in\left\{\alpha_{1} \mid 0 \leq \alpha_{1} \leq 0.8\right\}\right.$, $\alpha_{2} \in\left\{\alpha_{2} \mid 0 \leq \alpha_{2} \leq \frac{38}{45}\right\}$ in Model S and $\alpha_{1} \in\left\{\alpha_{1} \mid 0 \leq \alpha_{1} \leq \frac{31}{45}\right\}, \alpha_{2} \in\left\{\alpha_{2} \mid 0 \leq \alpha_{2} \leq \frac{38}{45}\right\}$ in Model N).

Figure 4 verifies the monotonic properties of optimal prices, demands and profits in Models $\mathrm{S}$ and $\mathrm{N}$ with respect to parameters. As we can see, the prices of products, demands and profits of manufacturers all decrease with the increase of the proportion of consumers who only purchase products in the other period.

Some discussions about demands or prices sequences in Figure 4 are given in the following:

(1) In Model S, when the parameters meet the requirements, $p_{1}^{\mathrm{SI}}>p_{2}^{\mathrm{SI}}, p_{1}^{\mathrm{SII}}>p_{2}^{\mathrm{SII}}$. It means that the optimal prices of products of manufacturers with pricing priority is higher.

(2) $D_{1}^{\mathrm{SI}}<D_{12}^{\mathrm{NI}}<D_{2}^{\mathrm{SI}}, D_{1}^{\mathrm{SII}}<D_{2}^{\mathrm{SII}}<D_{12}^{\mathrm{NII}}$. This is a comparison of demands in the Models $\mathrm{S}$ and N.

(3) $\pi_{M}^{\mathrm{NI}}<\pi_{M_{1}}^{\mathrm{SI}}<\pi_{M_{2}}^{\mathrm{SI}}, \pi_{M_{1}}^{\mathrm{SII}}<\pi_{M_{2}}^{\mathrm{SII}}<\pi_{M}^{\mathrm{NII}}$. In the first period, the profits of manufacturers in the Model S were higher than those in the Model N. In the second period, the conclusion was reversed. In addition, the manufacturer with the pricing priority has lower profits in Model S.

We compare the two manufacturers' total profits in the Figure 5a. As we see, the Manufacturer 1's two period profits are lower than the Manufacturer 2's when they play a Stackelberg game. But when they reach Nash equilibrium, both of them can earn more most of the time. In fact, the price leader makes his best choice for his production's price, but it doesn't mean that the higher price can earn more. Lower price brings more demand and makes the price follower gets more profit.

Figure 5c shows the impact of $\alpha_{1}$ and $\alpha_{2}$ on $\pi_{M}^{N T}, \pi_{M_{1}}^{S T}$ and $\pi_{M_{2}}^{S T}$. We compare them in the region $\left\{\left(\alpha_{1}, \alpha_{2}\right) \mid 0 \leq \alpha_{1} \leq 0.84,0 \leq \alpha_{2} \leq 0.8,0 \leq \alpha_{1}+\alpha_{2} \leq 1\right\}$. The result is shown in Figure 5 d.

Figure 6 shows the value of the communication fees in the two periods, and their tendency to change with the value of $\alpha_{i}$. The communication fee in the first period is much larger than that in the second period. This is in line with the reality that the price of new technologies will decline as the technology matures. In the first period, the communication fees are the same regardless of the game method adopted by the manufacturers, but in the second period, the communication fee will be lower when the manufacturers adopt the Nash game. 


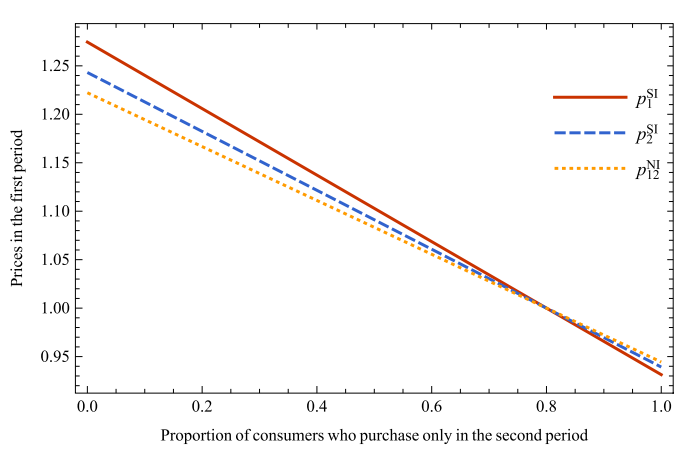

(a)

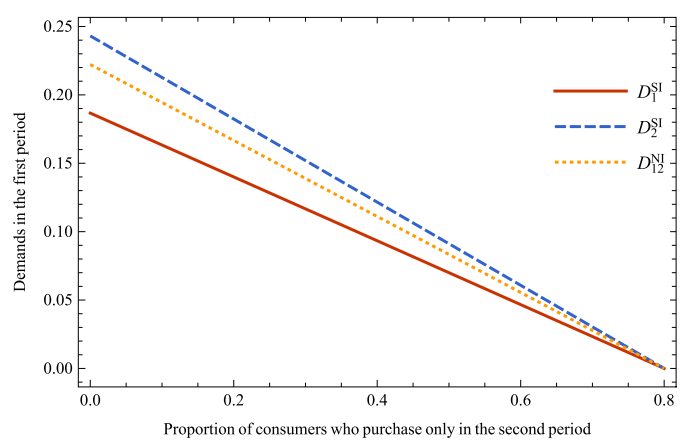

(c)

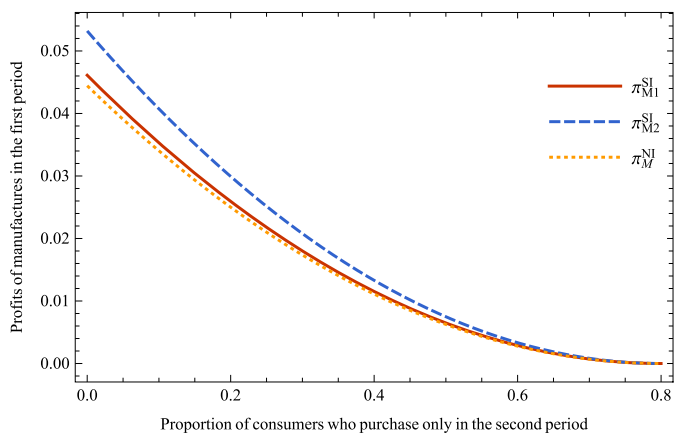

(e)

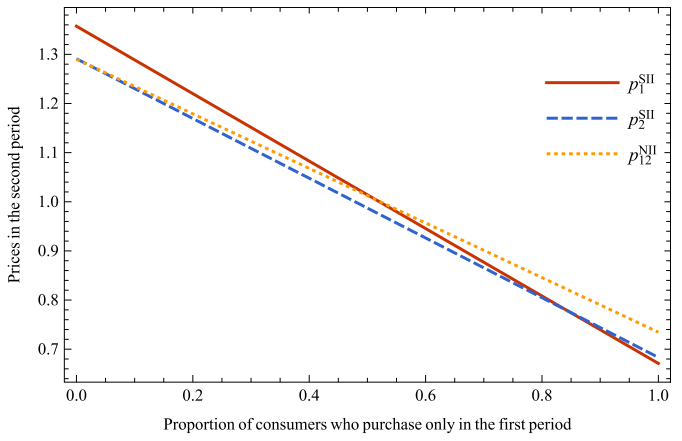

(b)

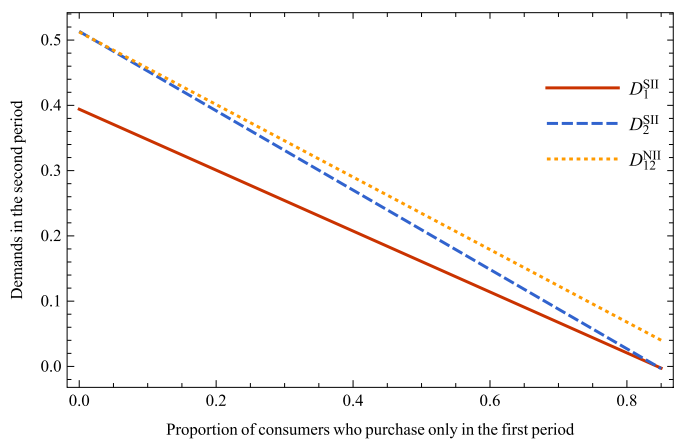

(d)

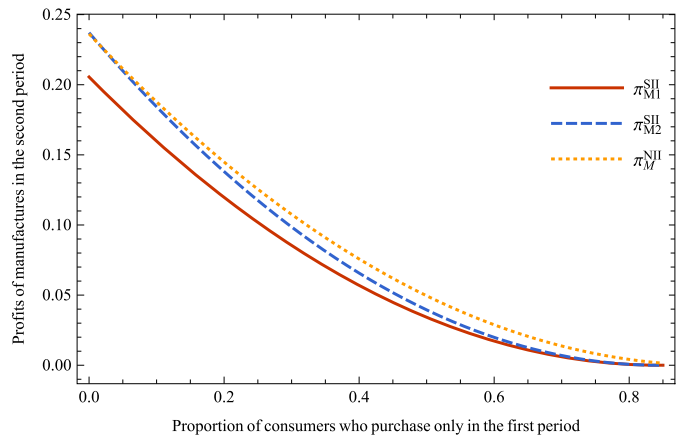

(f)

FiguRE 4. The impact of $\alpha_{1}$ or $\alpha_{2}$ on prices, demands and profits.

Figure 7 represents how the parameter $\alpha_{1}$ and $\alpha_{2}$ impact the communication operator's total profit. We can see that the operator earns more in the Model S. And it is shown in Figure 8 how the retailer's total profit changes with the impact of $\alpha_{1}$ and $\alpha_{2}$. Different from the operator, the retailer will get higher profit in the Model N. The discussions are as follows:

(1) When the values of $\alpha_{1}$ and $\alpha_{2}$ are determined, $\pi_{O}^{S T}>\pi_{O}^{N T}$. It means that a Stackelberg game between manufacturers is more profitable for the communication operator.

(2) When the values of $\alpha_{1}$ and $\alpha_{2}$ are determined, $\pi_{R}^{N T}>\pi_{R}^{S T}$. It means that the retailer's profit is higher when the manufacturer plays the Nash game. 


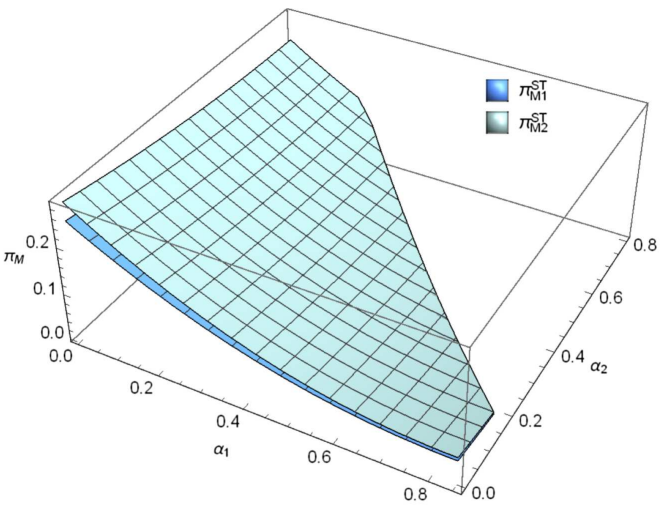

(a)

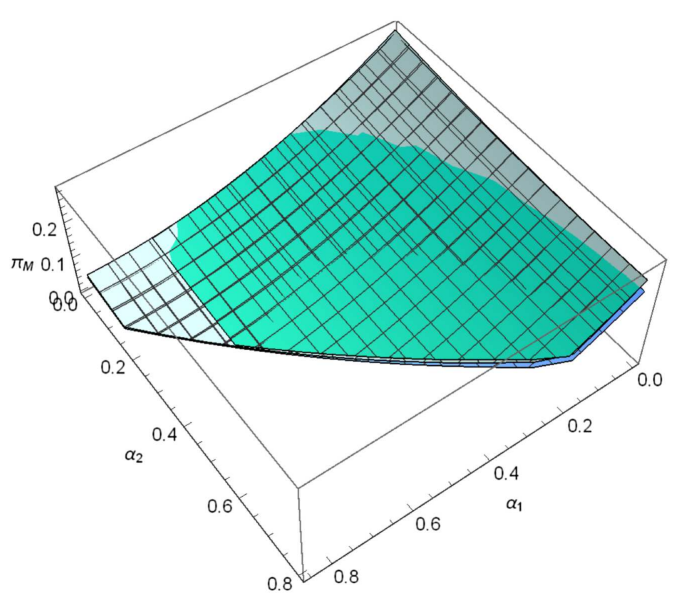

(c)

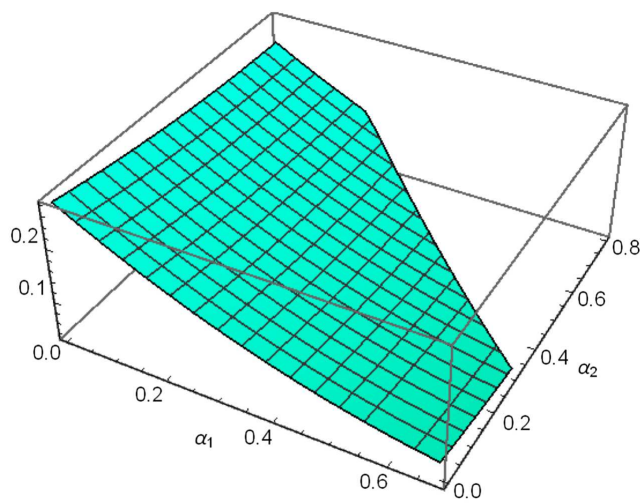

(b)

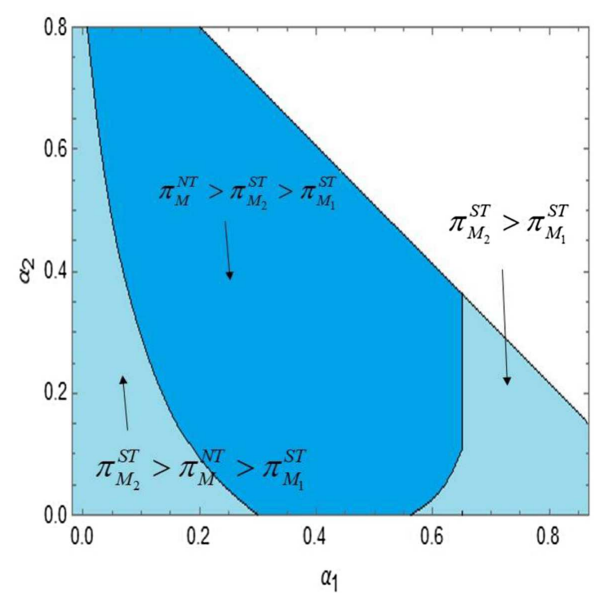

(d)

FiguRE 5 . The impact of $\alpha_{1}$ and $\alpha_{2}$ on $\pi_{M}$.
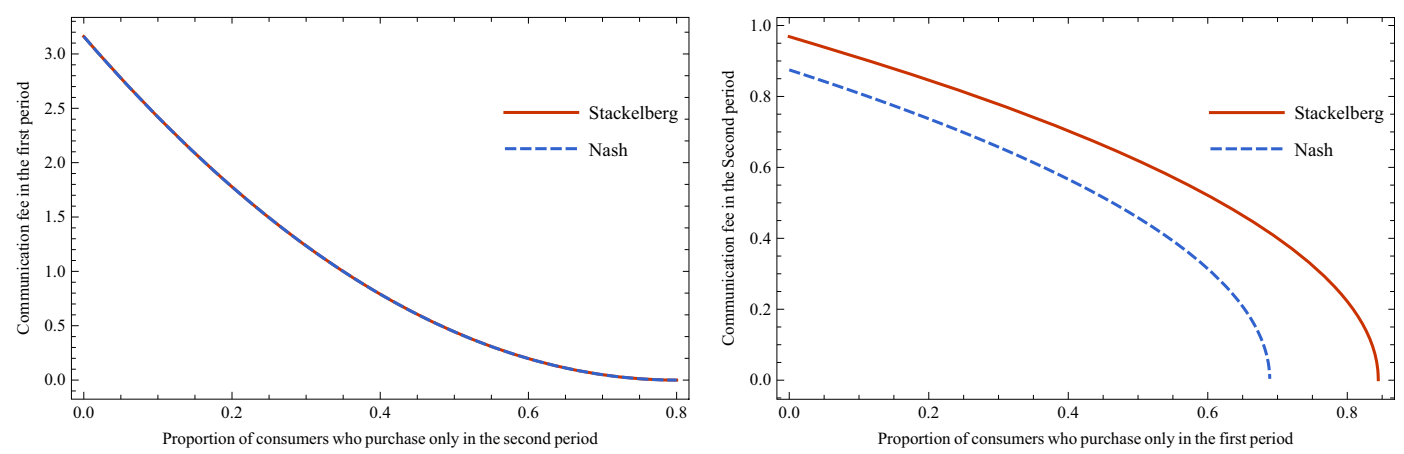

FiguRE 6 . The impact of $\alpha_{1}$ or $\alpha_{2}$ on communication fees. 


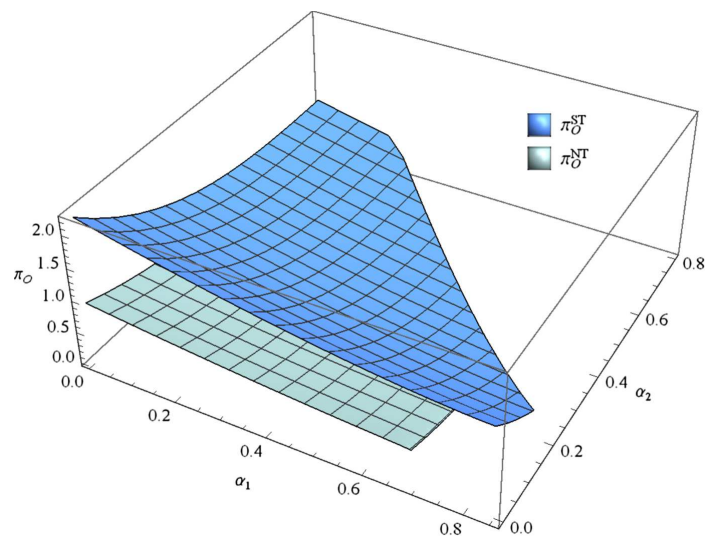

Figure 7. The impact of $\alpha_{1}$ and $\alpha_{2}$ on $\pi_{O}^{T}$.

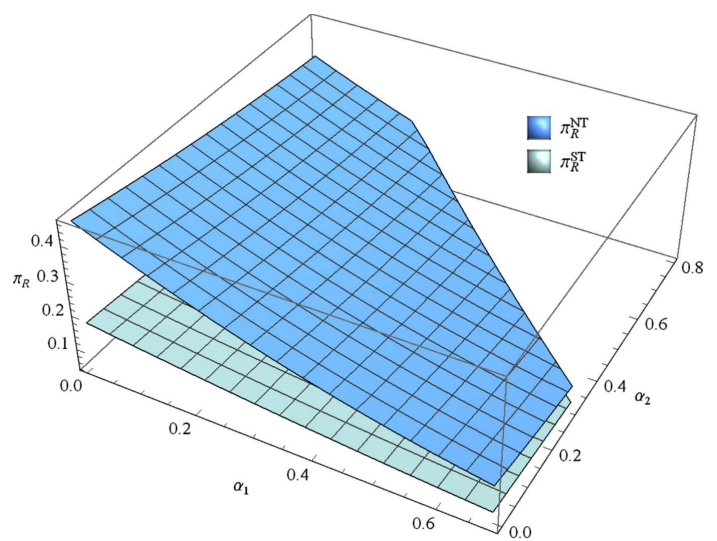

Figure 8. The impact of $\alpha_{1}$ and $\alpha_{2}$ on $\pi_{R}^{T}$.

Figures 9a and 9b imply the two-period profits of manufacturer 1, manufacturer 2, retailer, and operator as the value of $\alpha_{2}$ changes in the Model S. As we can see, the operator's profit is much higher than that of others. However, with the growth of the value of $\alpha_{2}$, its profit reduces fast and will be surpassed by the retailer when $\alpha_{2}=0.65$. But in the second period, the operator's profit will be higher than the manufacturers' and retailer's. Different from the first period, the retailer's profit is lower than two manufacturers' when the value of $\alpha_{1}$ is smaller. When manufacturers play a Nash game, the situation is similar (see Figs. 9c and 9d). Total profits of the supply chain members in the Models S and N are shown in the Figure 10. In Model S, the change of $\alpha_{2}$ has little effect on the comparison result, but when $\alpha_{1}$ gradually increases, the value of $\pi_{R}^{S T}$ starts to increase and thus exceeds $\pi_{M 1}^{S T}$ and $\pi_{M 2}^{S T}$ (see Fig. 10b). In Model N, when the values of $\alpha_{1}$ and $\alpha_{2}$ are close to $0.5, \pi_{R}^{N T}$ exceeds $\pi_{O}^{N T}$ and becomes the largest (see Fig. 10d).

\section{MANAGERIAL INSIGHT}

In our research, we establish a supply chain model contains two manufacturers, a communications operator and a mobile phone retailer. The cases where two manufacturers have the same or different pricing rights are researched by using the Stackelberg game and the Nash game model. We obtain the optimal 5G communication fees in two periods and find that the communication fee is much lower in the second period. In addition, we 


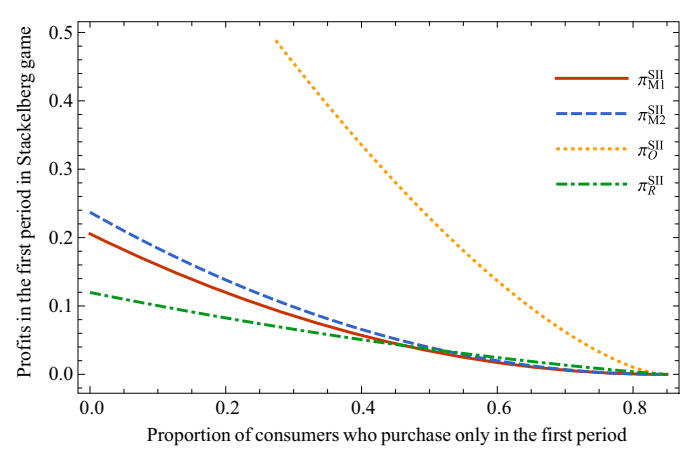

(a)

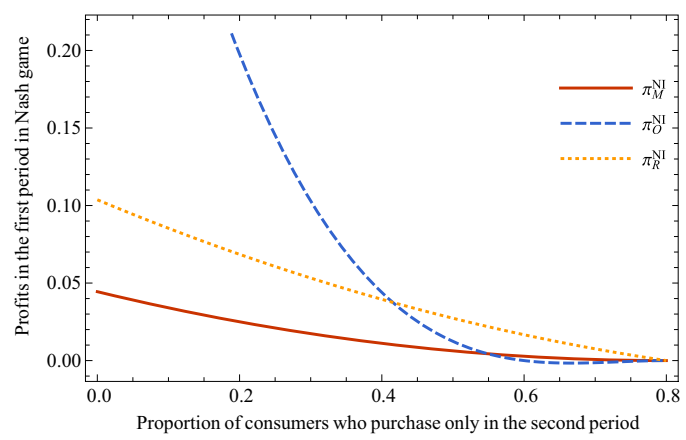

(c)

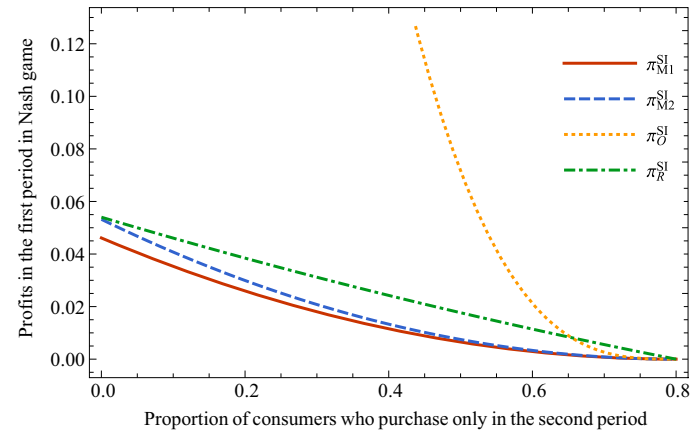

(b)

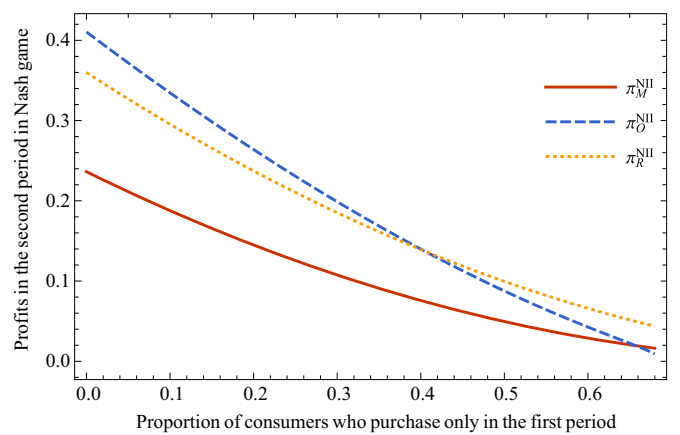

(d)

Figure 9. Two-period profits of supply chain in the Stackelberg and Nash games.

figure out the profits of the supply chain in two stages and analyze them. The operator earns the most and the supply chain profits are higher during the second period. Besides, we also investigate how the proportion of strategic consumer impact on supply chain profits.

Our research has enormous managerial insights in practical applications. In the current and future sales of 5G mobile phones, communication operators and manufacturers can optimally price products based on the proportion of strategic consumers in the market, which ensures that their profits are maximized. And mobile phone retailers can get more revenue by setting higher profit margins with manufacturers.

\section{Conclusion}

We have answered the research questions as follows.

(1) Considering the existence of strategic consumers in the market, how do the manufacturers and the communication operator price their phones and service in the two periods?

In two periods, when two manufacturers have different pricing power, the optimal price of a product of the manufacture with a higher pricing power is higher than that of the other manufacturer, but the market demand for its products will be less than the manufacturer with lower pricing power. When their pricing power is the same, they tend to set the price of the product at the same level, so that their market demand is the same. In each period, the optimal price and demand for the product will decrease and the gap between the prices and demands of the two manufacturers' products will become smaller when the proportion of consumers who purchase the product only in the other period increases.

(2) How does the proportion of strategic consumers impact on the profits of the supply chain? 


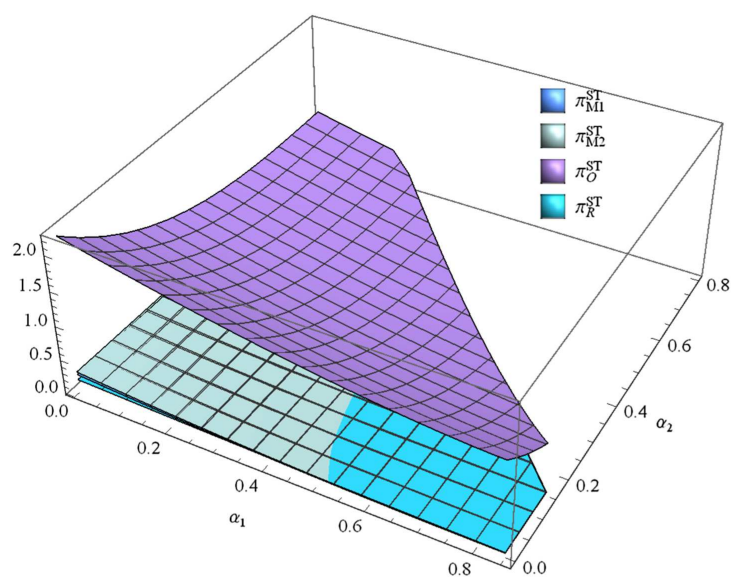

(a)

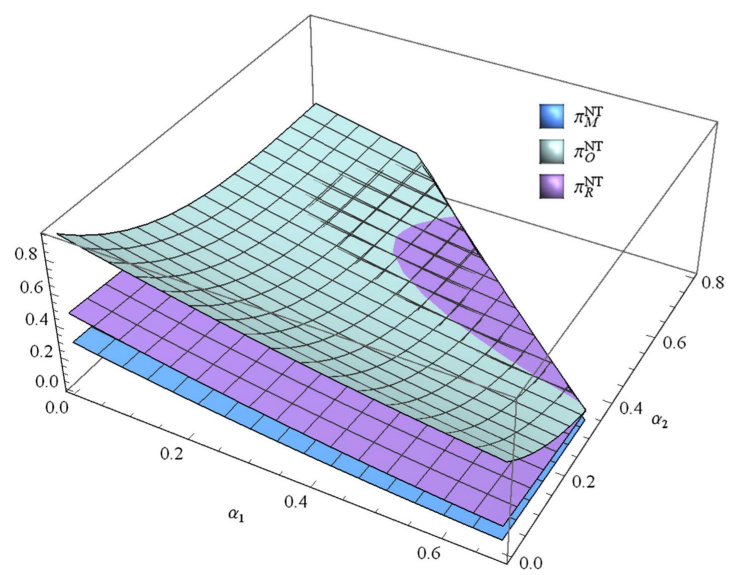

(c)

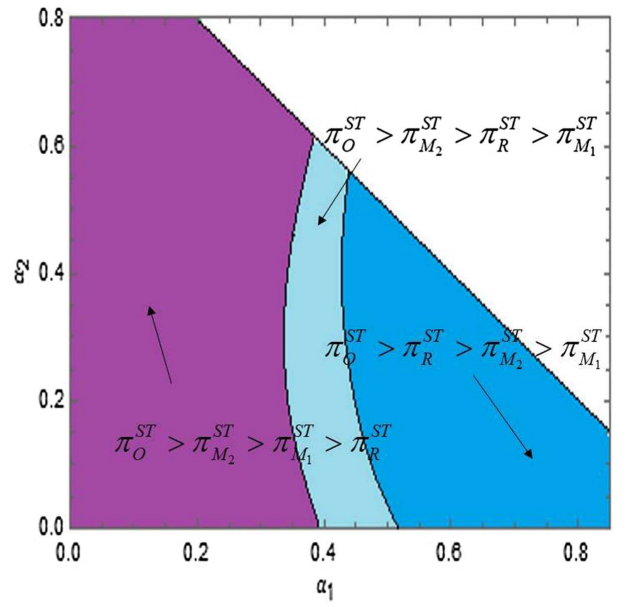

(b)

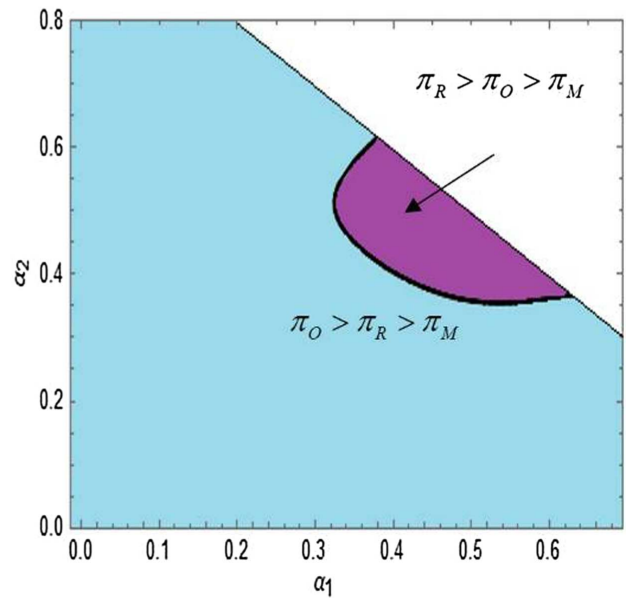

(d)

Figure 10. Total profits of supply chain in the Stackelberg and Nash games.

In each period, regardless of the pricing game method adopted by manufacturers, the profits of the members of the supply chain will decrease as the proportion of consumers who purchase products only in the other period increases. Among them, the profits of operators are the most affected. When considering the total profits of the two periods, we find that the profit of the communication operator is greatly affected by the proportion of consumers who purchase products only in the second period, when the proportion of consumers who only purchase products in the second period increases, its profits fell sharply. This trend is not obvious to the manufacturers and the retailer.

Our research is mainly to make a simulation of the sales of $5 \mathrm{G}$ mobile phones in the future. The results obtained can guide the participants in various supply chains. Different from previous studies, we take communication operators into account. However, our research has some limitations. We simplified the profit form of the supplier and changed the time-based fee to a one-time fee. This caused the communication fee in the article to be much higher than the mobile phone's price. It is a one-time charge, so there is not much difference with the result of charging by time. 
In the construction of the supply chain model, this article only uses a retail sales channel. To show the situation of mobile phone sales more comprehensively, you can increase direct sales channels, you can also add one or more retailers, and study the competition between retailers. Similar to the situation of mobile phone retailers, in the real mobile phone market, there is not only one communication operator. In this article, the price of communication service is only an influencing factor, so only one communication operator is added, so only one communication operator is added. A communication operator can study and analyze the pricing game among communication operators in further research. In addition, for the purpose of simplifying the model and highlighting the research focus, in this article, the communication service charge is a one-off, rather than the actual charge based on the length of use, and it does not consider the sales of contract machines by communication operators. Not the focus of this article, but these issues can be further studied later.

\section{Appendix A.}

Because $\frac{\partial^{2} \pi_{M_{2}}^{\mathrm{SI}}}{\partial p_{\mathrm{I} 2}^{2}}=2\left(1-r_{1}\right)\left(-1+\frac{\gamma^{2}}{2}\right)<0$ when $0<r_{1}<1,0<\gamma<1$, we can obtain $p_{\mathrm{I} 2}^{\mathrm{S}}=$ $\frac{-1-c_{1}-\gamma p_{\mathrm{I} 1}+r_{1}+\gamma p_{\mathrm{I} 1} r_{1}+\alpha_{2}-r_{1} \alpha_{2}+\lambda \sqrt{\beta_{1}}-\lambda r_{1} \sqrt{\beta_{1}}}{2\left(-1+r_{1}\right)}$ by solving the equation $\frac{\partial \pi_{M_{2}}^{\mathrm{SI}}}{\partial p_{\mathrm{I} 2}}=c_{1}-p_{\mathrm{I} 2}\left(1-r_{1}\right)+\left(1-r_{1}\right)$ $\left(1+\gamma p_{\mathrm{I} 1}-p_{\mathrm{I} 2}-\alpha_{2}-\lambda \sqrt{\beta_{1}}\right)=0$. Bring $p_{\mathrm{I} 2}^{\mathrm{S}} \quad$ into $\pi_{M_{1}}^{\mathrm{SI}}$ and solve the equation $\frac{\partial \pi_{M_{1}}^{\mathrm{SI}}}{\partial p_{\mathrm{I} 1}^{\mathrm{S}}}=$ $\frac{1}{2}\left(\left(2+\gamma-\gamma^{2}\right) c_{1}-\left(-1+r_{1}\right)\left(2\left(-2+\gamma^{2}\right) p_{\mathrm{I} 1}-(2+\gamma)\left(-1+\alpha_{2}+\lambda \sqrt{\beta_{1}}\right)\right)\right)=0\left(\frac{\partial^{2} \pi_{M_{1}}^{\mathrm{SI}}}{\partial p_{\mathrm{I}}^{2}}=2\left(1-r_{1}\right)\right.$ $\left(-1+\frac{\gamma^{2}}{2}\right)<0$ when $\left.0<r_{1}<1,0<\gamma<1\right)$, we can obtain $p_{\mathrm{I} 1}^{\mathrm{S}}=\frac{\left(2+\gamma-\gamma^{2}\right) c_{1}+(2+\gamma)\left(-1+r_{1}\right)\left(-1+\alpha_{2}+\lambda \sqrt{\beta_{1}}\right)}{2\left(-2+\gamma^{2}\right)\left(-1+r_{1}\right)}$, then we can get $p_{\mathrm{I} 2}^{\mathrm{S}}=\frac{\left(-4-2 \gamma+\gamma^{2}+\gamma^{3}\right) c_{1}+\left(-4-2 \gamma+\gamma^{2}\right)\left(-1+r_{1}\right)\left(-1+\alpha_{2}+\lambda \sqrt{\beta_{1}}\right)}{4\left(-2+\gamma^{2}\right)\left(1-r_{1}\right)}$. Bring $p_{\mathrm{I} 1}^{\mathrm{S}}$ and $p_{\mathrm{I} 2}^{\mathrm{S}}$ into equations (3.1) and (3.2), we can obtain the value of $D_{\mathrm{I} 1}^{\mathrm{S}}, D_{\mathrm{I} 1}^{\mathrm{S}}, \pi_{M_{1}}^{\mathrm{SI}}, \pi_{M_{2}}^{\mathrm{SI}}$. Use the same method, we can obtain $D_{\mathrm{II} 1}^{\mathrm{S}}, D_{\mathrm{II} 1}^{\mathrm{S}}, \pi_{M_{1}}^{\mathrm{SII}}, \pi_{M_{2}}^{\mathrm{SII}}$. Then we also know the value of $\pi_{R}^{\mathrm{SI}}, \pi_{R}^{\mathrm{SII}}, \pi_{O}^{\mathrm{SI}}, \pi_{O}^{\mathrm{SII}}$. They are all functions with $\beta_{1}$ and $\beta_{2}$.

Because $\frac{\partial^{2} \pi_{O}^{\text {SI }}}{\partial \beta_{1}^{2}}=-\frac{3\left(-8-4 \gamma+3 \gamma^{2}+\gamma^{3}\right) \lambda}{16\left(-2+\gamma^{2}\right) \sqrt{\beta_{1}}}<0$ when $\beta_{1}>0,0<\lambda<1,0<\gamma<1$, we can obtain $\beta_{1}=$ $\frac{4\left((-1+\gamma) c_{1}+\left(-1+y_{1}\right)\left(-1+\alpha_{2}\right)\right)^{2}}{9 \lambda^{2}\left(-1+y_{1}\right)^{2}}$ by solving the equation $\frac{\partial \pi_{\beta_{1}}^{\mathrm{SI}}}{\partial \beta_{1}}=-\frac{\left(-8-4 \gamma+3 \gamma^{2}+\gamma^{3}\right)\left((-1+\gamma) c_{1}+\left(-1+r_{1}\right)\left(-1+\alpha_{2}+\lambda \sqrt{\beta_{1}}\right)\right)}{4\left(-2+\gamma^{2}\right)\left(-1+r_{1}\right)}-$ $\frac{\left(-8-4 \gamma+3 \gamma^{2}+\gamma^{3}\right) \lambda \sqrt{\beta_{1}}}{8\left(-2+\gamma^{2}\right)}=0$, and because $\frac{\partial^{2} \pi_{O}^{\mathrm{SII}}}{\partial \beta_{2}^{2}}=-\frac{3\left(-8-4 \gamma+3 \gamma^{2}+\gamma^{3}\right) \lambda \beta_{2}}{2\left(-2+\gamma^{2}\right)}<0$ when $\beta_{2}>0,0<\lambda<1,0<$ $\gamma<1$. We can obtain $\beta_{2}^{2}=\frac{-1+c_{2}-\gamma c_{2}+r_{2}+\alpha_{1}-r_{2} \alpha_{1}}{3 \lambda\left(-1+r_{2}\right)}$ by solving the equation $\frac{\partial \pi_{O}^{\text {SII }}}{\partial \beta_{2}}=-\frac{\left(-8-4 \gamma+3 \gamma^{2}+\gamma^{3}\right) \lambda \beta_{2}^{2}}{2\left(-2+\gamma^{2}\right)}-$ $\frac{\left(-8-4 \gamma+3 \gamma^{2}+\gamma^{3}\right)\left((-1+\gamma) c_{2}+\left(-1+r_{2}\right)\left(-1+\alpha_{1}+\lambda \beta_{2}^{2}\right)\right)}{4\left(-2+\gamma^{2}\right)\left(-1+r_{2}\right)}=0$. And when $0<c_{2}<\frac{-1+r_{2}}{-1+\gamma}, 0<\alpha_{1}<\frac{-1+c_{2}-\gamma c_{2}+r_{2}}{-1+r_{2}}$, we can get $\beta_{2}^{\mathrm{S}}=\sqrt{\frac{(-1+\gamma) c_{2}+\left(-1+r_{2}\right)\left(-1+\alpha_{1}\right)}{3\left(1-r_{2}\right) \lambda}}$.

When $0<c_{1} \leq \frac{-1+r_{1}}{-1+\gamma}, \frac{-1+c_{1}-\gamma c_{1}+r_{1}}{-1+r_{1}}<\alpha_{2}<1$ or $c_{1}>\frac{-1+r_{1}}{-1+\gamma}, 0<\alpha_{2}<1$, we can obtain $\sqrt{\beta_{1}^{S}}=\frac{2\left((-1+\gamma) c_{1}+\left(-1+r_{1}\right)\left(-1+\alpha_{2}\right)\right)}{3 \lambda\left(-1+r_{1}\right)}$. When $0<c_{1}<\frac{-1+r_{1}}{-1+\gamma}, 0<\alpha_{2}<\frac{-1+c_{1}-\gamma c_{1}+r_{1}}{-1+r_{1}}$, we can obtain $\sqrt{\beta_{1}^{\mathrm{S}}}=\frac{2\left((-1+\gamma) c_{1}+\left(-1+r_{1}\right)\left(-1+\alpha_{2}\right)\right)}{3 \lambda\left(1-r_{1}\right)}$.

In our research, in order to simplify the next analysis and make it in line with reality, we can simply make $\sqrt{\beta_{1}^{S}}=\frac{2\left((-1+\gamma) c_{1}+\left(-1+r_{1}\right)\left(-1+\alpha_{2}\right)\right)}{3 \lambda\left(1-r_{1}\right)}$. And then we can put $\sqrt{\beta_{1}}$ and $\beta_{2}^{2}$ into the functions of prices, demands and profits, we can get the equations (4.1)-(4.4).

\section{Appendix B.}

When the two manufacturers play a Nash game, the solution process is as follows.

We can firstly verify $\frac{\partial^{2} \pi_{M 1}^{\mathrm{NI}}}{\partial p_{\mathrm{I1}}^{2}}<0, \frac{\partial^{2} \pi_{M 2}^{\mathrm{NI}}}{\partial p_{12}^{2}}<0$. By solving $\frac{\partial \pi_{M 1}^{\mathrm{NI}}}{\partial p_{\mathrm{I} 1}}=c_{1}-p_{\mathrm{I} 1}\left(1-r_{1}\right)+\left(1-r_{1}\right)$ $\left(1-p_{\mathrm{I} 1}+\gamma p_{\mathrm{I} 2}-\alpha_{2}-\lambda \sqrt{\beta_{1}}\right)=0$ and $\frac{\partial \pi_{M_{2}}^{\mathrm{NI}}}{\partial p_{\mathrm{I} 2}}=c_{1}-p_{\mathrm{I} 2}\left(1-r_{1}\right)+\left(1-r_{1}\right)\left(1+\gamma p_{\mathrm{I} 1}-p_{\mathrm{I} 2}-\alpha_{2}-\lambda \sqrt{\beta_{1}}\right)=0$, we 
can obtain the prices and demands of the products in the first period, that is,

$$
\begin{aligned}
& p_{1}^{\mathrm{NI}}=p_{2}^{\mathrm{NI}}=-\frac{-1-c_{1}+r_{1}+\alpha_{2}-r_{1} \alpha_{2}+\lambda \sqrt{\beta_{1}}-\lambda r_{1} \sqrt{\beta_{1}}}{(-2+\gamma)\left(-1+r_{1}\right)}, \\
& D_{1}^{\mathrm{NI}}=D_{2}^{\mathrm{NI}}=\frac{(-1+\gamma) c_{1}+\left(-1+r_{1}\right)\left(-1+\alpha_{2}+\lambda \sqrt{\beta_{1}}\right)}{(-2+\gamma)\left(-1+r_{1}\right)} .
\end{aligned}
$$

Use the same method, we can get the prices and demands of the products in the second period,

$$
\begin{gathered}
p_{1}^{\mathrm{NII}}=p_{2}^{\mathrm{NII}}=-\frac{-1-c_{2}+r_{2}+\alpha_{1}-r_{2} \alpha_{1}+\lambda \beta_{2}^{2}-\lambda r_{2} \beta_{2}^{2}}{(-2+\gamma)\left(-1+r_{2}\right)}, \\
D_{1}^{\mathrm{NII}}=D_{2}^{\mathrm{NII}}=\frac{(-1+\gamma) c_{2}+\left(-1+r_{2}\right)\left(-1+\alpha_{1}+\lambda \beta_{2}^{2}\right)}{(-2+\gamma)\left(-1+r_{2}\right)} .
\end{gathered}
$$

Put them into the equation (3.4), we can obtain

$$
\begin{aligned}
\pi_{O}^{\mathrm{NI}} & =\frac{2(-1+\gamma) c_{1}+\left(-1+r_{1}\right)\left(-1+\alpha_{2}+\lambda \sqrt{\beta_{1}}\right) \beta_{1}}{(-2+\gamma)\left(-1+r_{1}\right)}, \\
\pi_{O}^{\mathrm{NII}} & =\frac{2(-1+\gamma) c_{2}+\left(-1+r_{2}\right)\left(-1+\alpha_{1}+\lambda \beta_{2}^{2}\right) \beta_{2}}{(-2+\gamma)\left(-1+r_{2}\right)} .
\end{aligned}
$$

We can firstly verify $\frac{\partial^{2} \pi_{O}^{\mathrm{NI}}}{\partial \beta_{1}^{2}}<0, \frac{\partial^{2} \pi_{O}^{\mathrm{NII}}}{\partial \beta_{2}^{2}}<0$. By solving $\frac{\partial \pi_{O}^{I}}{\partial \beta_{1}}=0, \frac{\partial \pi_{O}^{\mathrm{II}}}{\partial \beta_{2}}=0$, we can get the communication fees in two periods, that is, $\beta_{1}^{\mathrm{N}}=\frac{4\left((-1+\gamma) c_{1}+\left(-1+r_{1}\right)\left(-1+\alpha_{2}\right)\right)^{2}}{9 \lambda^{2}\left(-1+r_{1}\right)^{2}}, \beta_{2}^{\mathrm{N}}=$ $\sqrt{\frac{-1+2 c_{2}-2 \gamma c_{2}+r_{2}+\alpha_{1}-r_{2} \alpha_{1}}{3 \lambda\left(-1+r_{2}\right)}} \quad\left(0<c_{2}<\frac{-1+r_{2}}{-2+2 \gamma}, 0<c_{1}<\frac{-1+r_{1}}{-1+\gamma}, 0<\alpha_{1}<\frac{-1+2 c_{2}-2 \gamma c_{2}+r_{2}}{-1+r_{2}}, 0<\alpha_{2}<\frac{-1+c_{1}-\gamma c_{1}+r_{1}}{-1+r_{1}}\right)$. Put the parameter $\beta_{1}^{\mathrm{N}}$ and $\beta_{2}^{\mathrm{N}}$ into $p_{1}^{\mathrm{NI}}, p_{2}^{\mathrm{NI}}, p_{1}^{\mathrm{NII}}, p_{2}^{\mathrm{NII}}, D_{1}^{\mathrm{NI}}, D_{2}^{\mathrm{NI}}, D_{1}^{\mathrm{NII}}, D_{2}^{\mathrm{NII}}$, we can get the results.

\section{REFERENCES}

[1] M.J. Arshad, A. Farooq and A. Shah, Evolution and development towards 4th generation (4G) mobile communication systems. J. Am. Sci. 6 (2010) 63-68.

[2] B. Bao, J. Ma and M. Goh, Short- and long-term repeated game behaviours of two parallel supply chains based on government subsidy in the vehicle market. Int. J. Prod. Res. 58 (2020) 7507-7530.

[3] G.P. Cachon and P. Feldman, Price commitments with strategic consumers: Why it can be optimal to discount more frequently than optimal. Manuf. Serv. Oper. Manage. 17 (2015) 399-410.

[4] M. Cheng, T. Hsieh, H. Lee and L.Y. Ouyang, Optimal ordering policies for deteriorating items with a return period and price-dependent demand under two-phase advance sales. Oper. Res. Int. J. 20 (2020) 585-604.

[5] P. De Giovanni and G. Zaccour, A two-period game of a closed-loop supply chain. Eur. J. Oper. Res. 232 (2014) $22-40$.

[6] J. Dong and D.D. Wu, Two-period pricing and quick response with strategic consumers. Int. J. Prod. Econ. 215 (2019) $165-173$.

[7] A. Farshbaf-Geranmayeh and G. Zaccour, Pricing and advertising in a supply chain in the presence of strategic consumers. Omega 101 (2020) 102239.

[8] T.S. Genc and P. De Giovanni, Trade-in and save: a two-period closed-loop supply chain game with price and technology dependent returns. Int. J. Prod. Econ. 183 (2017) 514-527.

[9] P. He, H. Feng, G. Hu, K. Hewage, G. Achari, C. Wang and R. Sadiq, Life cycle cost analysis for recycling high-tech minerals from waste mobile phones in China. J. Clean Prod. 251 (2020) 119498.

[10] ITU, Time series of ICT data for the world, by geographic regions and by level of development, for the following indicators. Accessed 28 October 2019. https://www.itu.int/en/ITU-D/Statistics/Pages/stat/default.aspx (2019).

[11] G. Kalyanaram and J.D. Little, An empirical analysis of latitude of price acceptance in consumer package goods. J. Consum. Res. 21 (1994) 408-418.

[12] D.J. Langley, J. van Doorn, I.C. Ng, S. Stieglitz, A. Lazovik and A. Boonstra, The internet of everything: smart things and their impact on business models. J. Bus Res. 122 (2021) 853-863.

[13] Q. Lei, J. He and F. Huang, Impacts of online and offline channel structures on two-period supply chains with strategic consumers. Mathematics 8 (2020) 34. 
[14] C. Li, M. Chu, C. Zhou and L. Zhao, Two-period discount pricing strategies for an e-commerce platform with strategic consumers. Comput. Ind. Eng. 147 (2020) 106640.

[15] J. Liu, X. Zhai and L. Chen, Optimal pricing strategy under trade-in program in the presence of strategic consumers. Omega $\mathbf{8 4}$ (2019) 1-17.

[16] J. Ma, Y. Hou, W. Yang and Y. Tian, A time-based pricing game in a competitive vehicle market regarding the intervention of carbon emission reduction[J]. Energy Policy 142 (2020) 111440.

[17] J. Ma, Y. Hou, Z. Wang and W. Yang, Pricing strategy and coordination of automobile manufacturers based on government intervention and carbon emission reduction[J]. Energy Policy 148 (2021) 111919.

[18] K. Maeng, J. Kim and J. Shin, Demand forecasting for the 5G service market considering consumer preference and purchase delay behavior. Telemat. Inf. 47 (2020) 101327.

[19] T. Maiti and B.C. Giri, Two-period pricing and decision strategies in a two-echelon supply chain under price-dependent demand. Appl. Math. Model. 42 (2017) 655-674.

[20] J.A. Niederhoff and P. Kouvelis, Generous, spiteful, or profit maximizing suppliers in the wholesale price contract: a behavioral study. Eur. J. Oper. Res. 253 (2016) 372-382.

[21] A.K. Parlaktürk, The value of product variety when selling to strategic consumers. Manuf. Ser. Oper. Manage. 14 (2012) 371-385.

[22] Y. Papanastasiou and N. Savva, Dynamic pricing in the presence of social learning and strategic consumers. Manage. Sci. 63 (2017) 919-939.

[23] X. Su, Optimal pricing with speculators and strategic consumers. Manage. Sci. 56 (2010) 25-40.

[24] L. Xie, J. Ma and M. Goh, Supply chain coordination in the presence of uncertain yield and demand. Int. J. Prod Res. (2020). DOI: $10.1080 / 00207543.2020 .1762942$.

[25] H. Zaman and G. Zaccour, Optimal government scrappage subsidies in the presence of strategic consumers. Eur. J. Oper. Res. 288 (2021) 829-838.

[26] Y. Zha, L. Zhang, C. Xu and T. Zhang, A two-period pricing model with intertemporal and horizontal reference price effects. Int. Trans. Oper. Res. 288 (2021) 829-838.

[27] E. Zhou, J. Zhang, Q. Gou and L. Liang, A two-period pricing model for new fashion style launching strategy. Int. J. Prod. Econ. 160 (2015) 144-156. 